\title{
Prevalence and correlates of coronary heart disease: first population-based study in Lebanon
}

This article was published in the following Dove Press journal:

Vascular Health and Risk Management

17 March 2016

Number of times this article has been viewed

\section{Rouba Karen Zeidan' \\ Rita Farah ${ }^{2}$ \\ Mirna N Chahine ${ }^{3}$ \\ Roland Asmar ${ }^{3}$ \\ Hassan Hosseini $i^{4,5}$ \\ Pascale Salameh ${ }^{6,7}$ \\ Atul Pathak ${ }^{8}$}

'Doctoral School of Biology Health and Biotechnologies, Toulouse III

University, Toulouse, ${ }^{2}$ Doctoral School of Life and Health Sciences, Paris-Est University, Creteil, France; ${ }^{3}$ Foundation-Medical Research Institutes, F-MRI ${ }^{\circledR}$, Beirut, Lebanon; ${ }^{4}$ Department of Neurology, Henri Mondor Hospital AP-HP, ${ }^{5}$ EA 439I, Nerve Excitability and Therapeutics, Université Paris-Est, Creteil, France; ${ }^{6}$ School of Pharmacy, Lebanese American University, Byblos, ${ }^{7}$ Laboratory of Clinical and Epidemiology Research, Faculty of Pharmacy, Lebanese University, Hadath, Lebanon; ${ }^{8}$ Department of Cardiovascular Medicine, Hypertension, Risk Factors and Heart Failure Unit, Clinique Pasteur. Toulouse, France
Correspondence: Rouba Karen Zeidan Apt 104, 4 Avenue des Herbettes, 31400 Toulouse, France

Tel +96I 3197567

Email roubakaren@gmail.com
Background: Lebanon is experiencing a growing epidemic of coronary heart diseases (CHDs), as most low- and middle-income countries currently are. However, this growth can be attenuated if effective preventive strategies are adopted.

Purpose: To provide the first national population-based prevalence of CHD and to describe the profile of Lebanese adults with prevalent CHD.

Methods: We carried out a cross-sectional study using a multistage cluster sample across Lebanon. We interviewed residents aged 40 years and older using a questionnaire that captured the presence of CHDs and their risk factors (RFs).

Results: Our study showed that $13.4 \%$ of the Lebanese population aged $\geq 40$ years suffer from a prevalent CHD. CHD seemed to appear more prematurely than in developed countries, and males seemed to be more subject to CHD than females until a certain age. CHD was associated with older age, male sex, a lower economic situation, hypercholesterolemia, hypertension, having a family history of premature cardiovascular diseases, and suffering from diabetes. However, smoking and waist circumference did not seem to have an independent effect on CHD, but rather an effect mediated by biological RFs.

Conclusion: This is the first nationwide endeavor conducted in Lebanon to assess the prevalence of CHD. This study also confirms the relevance of the classic RFs of CHD and their applicability to the Lebanese population, thus allowing for prevention strategies.

Keywords: coronary heart disease, correlates, epidemiology, prevalence, risk factors

\section{Introduction}

In 2010, ischemic heart disease was the leading cause of mortality worldwide. ${ }^{1}$ Projections reveal that ischemic heart disease mortality in the Middle Eastern countries will increase at a higher rate compared to the other regions. ${ }^{2,3}$ However, many acute myocardial infarction (MI) patients do survive, and many adults live with disabling symptoms related to coronary heart disease (CHD). ${ }^{1}$ Therefore, measuring the burden of $\mathrm{CHD}$ requires estimating nonfatal $\mathrm{CHD}$ prevalence.

Furthermore, the disease pathogenesis being multifactorial, studying the association of CHD with societal, lifestyle, and classic risk factors (RFs) in different settings is primordial to adopt effective preventive strategies by acting on the core causes, allowing for a significant reduction in the incidence and prevalence of CHD. ${ }^{4}$ However, local data to inform health policy are inadequate in the Eastern Mediterranean region. Specifically in Lebanon, a lack of nationally representative data on the epidemiology of CHD has been reported. ${ }^{5}$ In fact, a review of the literature reveals that no study on the prevalence of CHD in Lebanon has been carried out. As for the profiling of 
people at risk of $\mathrm{CHD}$, two studies were found; one focused on biological RFs, ${ }^{6}$ while the other explored socioeconomic disparities in heart disease. ${ }^{7}$

Our study was thus designed to determine a national population-based CHD prevalence in Lebanese people aged 40 years and older and to construct the profile of people living with CHD, using social, behavioral, and biological factors, in order to provide a more holistic image of the burden. This will allow more efficient and targeted health services.

\section{Methods}

\section{Study design and population}

The methodology presented in this paper has been previously described elsewhere. ${ }^{8}$ The data for this study were collected through a cross-sectional study, carried out between September 2013 and October 2014, using a multistage cluster sample across Lebanon. One hundred circumscriptions were randomly selected from the list of circumscriptions in Lebanon. From the list of dwellers provided by the local authorities, the selection of residents aged $\geq 40$ years was done using a software program to ensure randomness. Data were gathered from a face-to-face interview from participants who provided an oral and written consent. The Institutional Review Board (IRB) of the Lebanese University waived the need for ethical approval since this is an observational study with no traceability of subjects. Individuals with learning disabilities or psychiatric disorders were excluded.

\section{Sample size}

Sample size was initially calculated to measure the prevalence of cardiovascular RFs. We used Epi Info ${ }^{\mathrm{TM}}$ (Center for Disease Control, Atlanta, GA, USA. Available from: http://wwwn.cdc. gov/epiinfo/). Since no other figure was available, we used the prevalence of hypertension (43.1\% among individuals aged $\geq 50$ years) as the reference; ${ }^{9}$ after taking into account a worst acceptable result of $\pm 4 \%$ difference with the aforementioned prevalence and a $95 \%$ confidence interval (CI) as well as the two-stage sampling design, a minimal sample size of 1,200 was required in a population over 40 years of age.

\section{Data collection}

The first section of the questionnaire captured the sociodemographic characteristics of the participants. We also asked about educational level, income, and the number of people per household to evaluate the economic situation of participants. This was followed by a second section where information about the presence of CHD was collected. Then, the presence of the main CHD RFs was assessed.

\section{Measurements}

Anthropometric measurements included weight (in $\mathrm{kg}$ ), height (in $\mathrm{m}$ ), and waist circumference (WC) (in $\mathrm{cm}$ ). Systolic blood pressure (SBP) and diastolic blood pressure (DBP) were measured twice following a standardized protocol using an electronic automatic validated device, the Omron ${ }^{\circledR}$ M6 Comfort (Omron ${ }^{\circledR}$, Kyoto, Japan). ${ }^{10}$ Random capillary blood glucose (RCBG) was also measured using Accu-Check ${ }^{\circledR}$ Performa (Roche Diagnostics GmbH, Mannheim, Germany). All measurements were performed by trained medical students. The body mass index (BMI) was then calculated by dividing weight in kilograms by height in meters squared, and was divided into three categories: normal weight (BMI $<25 \mathrm{~kg} / \mathrm{m}^{2}$ ), overweight $\left(25 \mathrm{~kg} / \mathrm{m}^{2} \leq \mathrm{BMI}<30 \mathrm{~kg} / \mathrm{m}^{2}\right)$, and obese $\left(\mathrm{BMI} \geq 30 \mathrm{~kg} / \mathrm{m}^{2}\right)$.

\section{$\mathrm{CHD}$ definitions}

Participants who reported having suffered from a previous MI or having had percutaneous coronary intervention (PCI) or coronary artery bypass graft (CABG) were considered MI-, PCI-, or CABG-positive, respectively. Angina was defined using the "definite angina" definition of the Rosa Angina Questionnaire. ${ }^{11}$ To establish the lifetime prevalence of a $\mathrm{CHD}$, prevalence of $\mathrm{MI}$, angina pectoris, PCI, or CABG was summarized.

\section{Behavioral RF definitions}

To capture insufficient physical activity, type and frequency of exercise were self-reported. For each activity, we assigned the corresponding metabolic equivalent (MET) value, then a categorization into light-intensity (1.6-2.9 METs), moderateintensity (3-5.9 METs), and vigorous-intensity ( $\geq 6$ METs) activities was done based on the updated Compendium of Physical Activities. ${ }^{12}$ Insufficient physical activity was defined based on the World Health Organization (WHO) recommendations as less than 150 minutes of light- or moderate-intensity exercise/week and less than 75 minutes of vigorous-intensity exercise/week. ${ }^{13}$ Current smokers were defined as individuals who smoked cigarette and/or waterpipe in the previous 12 months and those who had quit within the past year. Participants who had quit more than a year earlier were considered former smokers. ${ }^{14}$ For ever-smokers, cumulative dosing of cigarettes was calculated as the average number of daily packs multiplied by the corresponding duration of smoking (pack $\times$ years), while that of waterpipe was calculated as the mean number of weekly waterpipes multiplied by the duration of smoking (waterpipe $\times$ years). ${ }^{15}$ To assess psychological distress, we used a scale that was developed and 
validated in Lebanon, the Beirut Distress Scale (BDS-22). Possible scores range from 0 to 66 (maximum psychological distress). ${ }^{16}$ Dietary habits were assessed using the Lebanese Mediterranean Diet Score, a dietary intake questionnaire for the quantitative estimation of adherence to a Mediterranean diet (MD) adapted to the Lebanese context, ranging from 0 to 52 (maximal adherence). ${ }^{17}$

\section{Biological RF definitions}

Hypertension was defined as having an average SBP of $\geq 140$ $\mathrm{mmHg}$ or an average DBP of $\geq 90 \mathrm{mmHg}$ or as current use of blood pressure-lowering medication. ${ }^{18}$ People who reported having hypertension were also considered hypertensive. ${ }^{14}$ Diabetes was defined as the composite of self-reported diabetes, $\mathrm{RCBG}>11.11 \mathrm{mmol} / \mathrm{L}$, or self-reported medication use for glucose control. ${ }^{19}$ Participants were asked if they suffered from hypercholesterolemia or hypertriglyceridemia. Their answers were double-checked with laboratory test results or medication when available. A family history of premature cardiovascular disease (CVD) was defined as a first-degree relative having manifested any CVD before the age of 55 years for males and 65 years for females. ${ }^{20,21}$

\section{Statistical analysis}

Two independent observers double-checked the quality of the questionnaires; an additional audit was performed on a randomized 5\% of the questionnaires. To adjust for the Lebanese population, we performed weighting based on the figures published by the Lebanese Ministry of Social Affairs and the Central Administration of Statistics, taking into account sex, age, and dwelling region. ${ }^{22}$ Age standardization was then done using the WHO standard population. ${ }^{23}$ All analyses were done using SPSS, version $21 \cdot 0$ (IBM Corporation, Armonk, NY, USA). Cluster effect was taken into account, according to the method described by Rumeau-Rouquette et $\mathrm{al},{ }^{24}$ and we used the SPSS features that take into account this sampling design. Participants with missing information concerning the presence of CHD were removed from the analysis. For normally distributed data, description was done using the mean and standard deviation (SD), while Student's $t$-test was used to compare mean between two groups and more than two groups, respectively. For continuous data that were not normally distributed, the median and the interquartile range were used for description, and the Mann-Whitney test was used for comparison. As for categorical variables, we used percentages with $95 \%$ CIs and the Pearson chi-square test. $P$-trends were calculated to measure the prevalence trends across the different age groups. A bivariate analysis measuring the association of the different sociodemographic characteristics, and behavioral and biological RFs with the presence or absence of CHD was done. We then performed multivariate analyses using logistic regression models only including selected variables, all of which had a $P$-value $\leq 0.2$ in the bivariate analysis. A $P$-value $\leq 0.05$ was considered statistically significant.

\section{Results}

The demographic characteristics of the sample are shown in Table 1.

\section{Prevalence of CHD}

CHD prevalences adjusted to the Lebanese population are presented in Table 2. The overall prevalence of MI, angina, PCI, and CABG was 6\% (4.9-7.4), 5.7\% (4.6-7.0), 6.6\% (5.4-8.1), and $3.9 \%(3.0-5.0)$, respectively. These prevalences were markedly different based on the sex of the person, males being more prone to CHD in general. However, in the age group of $70+$, the differences in prevalence between sexes were insignificant. Without stratifying by sex, an increase in prevalence was observed with advancing age for all CHD (all $P$-trend values were $<0.05$ ). The lifetime prevalence of MI ranged from $2.9 \%$

Table I Characteristics of the study participants

\begin{tabular}{ll}
\hline Characteristics & $\begin{array}{l}\text { Study participants } \\
(\mathbf{n}=\mathbf{I}, 362)\end{array}$ \\
\hline Age, in years, median (IQR) & $54(46-65)$ \\
Age groups & \\
$40-50$ years & $506(37.2)$ \\
$50-60$ years & $351(25.8)$ \\
$60-70$ years & $234(17.2)$ \\
$\geq 70$ years & $270(19.8)$ \\
Sex & \\
Males & $674(49.4)$ \\
Females & $689(50.6)$ \\
Region type & \\
Urban & $733(55.6)$ \\
Rural & $587(44.4)$ \\
Marital status & \\
Married & $1,064(78.6)$ \\
Single/widowed/divorced & $290(21.4)$ \\
Work status & \\
Working & $704(51.7)$ \\
Not working & $539(39.6)$ \\
Retired & $118(8.7)$ \\
Education level & \\
Complementary level or less & $678(50.3)$ \\
Secondary level or more & $671(49.7)$ \\
Income for each person of the household & 375,000 \\
(in Lebanese pounds), median $\pm(I Q R)$ & $(187,500-750,000)$ \\
\hline Note Datare &
\end{tabular}

Note: Data are presented as $n$ (percentage) unless indicated otherwise. Abbreviation: IQR, interquartile range. 
(1.8-4.7) in 40-49-year-old group to $9.2 \%(6.4-13.1)$ in $70+$ year-old group. In females, prevalence at 2.2\% (1.4-3.5) was less than the quarter of that in males at $10.1 \%(8.0-12.5)$ and prevalence was less than $0.4 \%(0.1-2.0)$ below age 50 . Also, less than $1 \%$ of males and females below the age of 50 had undergone a $\mathrm{CABG}$, while almost one in ten in the age of $70+$ had done the procedure. In females, prevalence of any CHD at $9.0 \%(7.1-11.4)$ was about half as high as that in males $(17.8 \%$ [15.1-20.9]). Almost one-quarter of Lebanese aged 70+ had at least one manifestation of CHD (Table 2). Figure 1 shows the prevalence of $\mathrm{CHD}$ after standardization was done using the WHO world standard population ${ }^{23}$ and shows an overall prevalence of $12.3 \%$ (10.8-14.1).

\section{Association of RFs and CHD}

\section{Bivariate analysis}

Table 3 shows the distribution of sociodemographic factors, and behavioral and biological RFs for people with and without prevalent CHD. The associated crude odds ratios (ORs) are also presented. CHD was more common with every higher age group. It was also more prevalent in males $(\mathrm{OR}=2.25,95 \% \mathrm{CI}=1.62-3.13)$ and in retired when compared to working subjects $(\mathrm{OR}=3.59,95 \% \mathrm{CI}=2.28-5.56)$. CHD was also more prevalent in participants with a lower education $(\mathrm{OR}=1.67,95 \% \mathrm{CI}=1.21-2.30)$ and with a lower income per person of the household $(\mathrm{OR}=1.81,95 \% \mathrm{CI}$ $=1.29-2.53$ ). Regarding risky behaviors, there were more previous smokers in the CHD-positive group (22.4\% vs $11.6 \%$ in the CHD-free group). Additionally, participants with a lifetime of 30 cigarette-pack-years or more were 2.39 times more likely to be in the CHD group in comparison with nonsmokers. In this study, obesity and abdominal obesity were found to be more common among the CHD group; also, all biological RFs were significantly and markedly more prevalent in the CHD group. The median SBP and RCBG values were higher among subjects with $\mathrm{CHD}(P<0.001)$, but

Table 2 Age- and sex-specific CHD prevalence adjusted for the Lebanese population

\begin{tabular}{|c|c|c|c|c|c|}
\hline $\begin{array}{l}\text { Coronary heart } \\
\text { diseases }\end{array}$ & $\begin{array}{l}\text { 40-49 years } \\
\%(95 \% \mathrm{Cl})\end{array}$ & $\begin{array}{l}50-59 \text { years } \\
\%(95 \% \mathrm{Cl})\end{array}$ & $\begin{array}{l}60-69 \text { years } \\
\%(95 \% \mathrm{Cl})\end{array}$ & $\begin{array}{l}\geq 70 \text { years } \\
\%(95 \% \mathrm{Cl})\end{array}$ & $\begin{array}{l}\text { Total } \\
\%(95 \% \mathrm{Cl})\end{array}$ \\
\hline \multicolumn{6}{|l|}{ MI } \\
\hline Male & $5.7(3.4-9.3)$ & | $2.8(8.7-\mid 8.4)$ & $12.3(7.6-19.3)$ & $12.3(7.9-18.6)$ & $10.1(8.0-12.5)$ \\
\hline Female & $0.4(0.1-2.0)$ & $2.1(0.8-5.3)$ & $1.7(0.5-5.9)$ & $6.2(3.3-11.3)$ & $2.2(1.4-3.5)$ \\
\hline$P\left(\chi^{2}\right)$ & $<0.001$ & $<0.001$ & 0.001 & 0.069 & $<0.001$ \\
\hline Overall & $2.9(1.8-4.7)$ & $7.3(5.0-10.4)$ & $7.0(4.4-11.0)$ & $9.2(6.4-13.1)$ & $6.0(4.9-7.4)$ \\
\hline$P$ trend & $<0.001$ & & & & \\
\hline \multicolumn{6}{|l|}{ Angina } \\
\hline Male & $5.7(3.4-9.3)$ & $8.4(5.2-13.2)$ & II.2 (6.8-17.9) & $9.7(5.8-15.9)$ & $8.2(6.4-10.5)$ \\
\hline Female & I.8 (0.8-4.2) & $3.9(1.9-7.8)$ & $4.0(1.7-9.1)$ & $4.7(2.3-9.4)$ & $3.3(2.2-4.9)$ \\
\hline$P\left(\chi^{2}\right)$ & 0.021 & 0.071 & 0.033 & 0.104 & $<0.001$ \\
\hline Overall & $3.7(2.4-5.7)$ & $6.2(4.2-9.2)$ & $7.6(4.9-1 \mathrm{I} .6)$ & 7.I (4.6-10.7) & $5.7(4.6-7.0)$ \\
\hline$P$ trend & 0.012 & & & & \\
\hline \multicolumn{6}{|l|}{$\mathrm{PCl}$} \\
\hline Male & I.2 (0.4-3.6) & I $2.3(8.3-17.9)$ & $17.6(\mid 1.8-25.5)$ & II.6 (7.4-17.9) & $9.2(7.2-11.6)$ \\
\hline Female & $1.5(0.6-3.8)$ & $1.6(0.6-4.6)$ & $5.0(2.3-10.6)$ & I I.8 (7.5-18.1) & $4.2(3.0-5.9)$ \\
\hline$P\left(\chi^{2}\right)$ & 0.794 & $<0.001$ & 0.002 & 0.966 & $<0.001$ \\
\hline Overall & $1.4(0.7-2.8)$ & $6.8(4.7-9.9)$ & II.3 (7.9-16.0) & II.7 (8.5-15.9) & $6.6(5.4-8.1)$ \\
\hline$P$ trend & $<0.001$ & & & & \\
\hline \multicolumn{6}{|l|}{ CABG } \\
\hline Male & $0.8(0.2-2.9)$ & $6.7(3.9-11.4)$ & $5.1(2.4-10.7)$ & I 3.7 (9.0-20.2) & $5.8(4.3-7.8)$ \\
\hline Female & 0 & $0.5(0.1-3.0)$ & $3.3(I .3-8 . I)$ & $6.8(3.6-12.5)$ & $2.0(1.2-3.3)$ \\
\hline$P\left(\chi^{2}\right)$ & 0.141 & 0.001 & 0.476 & 0.061 & $<0.001$ \\
\hline Overall & $0.4(0.1-1.4)$ & $3.6(2.1-6.0)$ & $4.1(2.3-7.5)$ & $10.4(7.4-\mid 4.6)$ & $3.9(3.0-5.0)$ \\
\hline$P$ trend & $<0.00 \mathrm{I}$ & & & & \\
\hline \multicolumn{6}{|l|}{ Any CHD } \\
\hline Male & $7(4.4-|| .0)$ & $22.7($ (I7.2-29.5) & $22.9(\mid 6.2-31.2)$ & $26.3(19.6-34.2)$ & $17.8(|5|-20.9)$. \\
\hline Female & $3.4(1.8-6.4)$ & $6.9(4.0-11.6)$ & $12.0(7.3-19.1)$ & $20.3(14.3-27.9)$ & $9.0(7.1-11.4)$ \\
\hline$P\left(\chi^{2}\right)$ & 0.066 & $<0.001$ & 0.027 & 0.246 & $<0.001$ \\
\hline Overall & $5.1(3.5-7.4)$ & I4.8 (II.5-|8.9) & $17.4(13.1-22.8)$ & 23.3 (I8.7-28.7) & I3.4 (II.7-|5.3) \\
\hline$P$ trend & $<0.001$ & & & & \\
\hline
\end{tabular}

Abbreviations: CHD, coronary heart disease; MI, myocardial infarction; PCl, percutaneous coronary intervention; CABG, coronary artery bypass graft; Cl, confidence interval. 


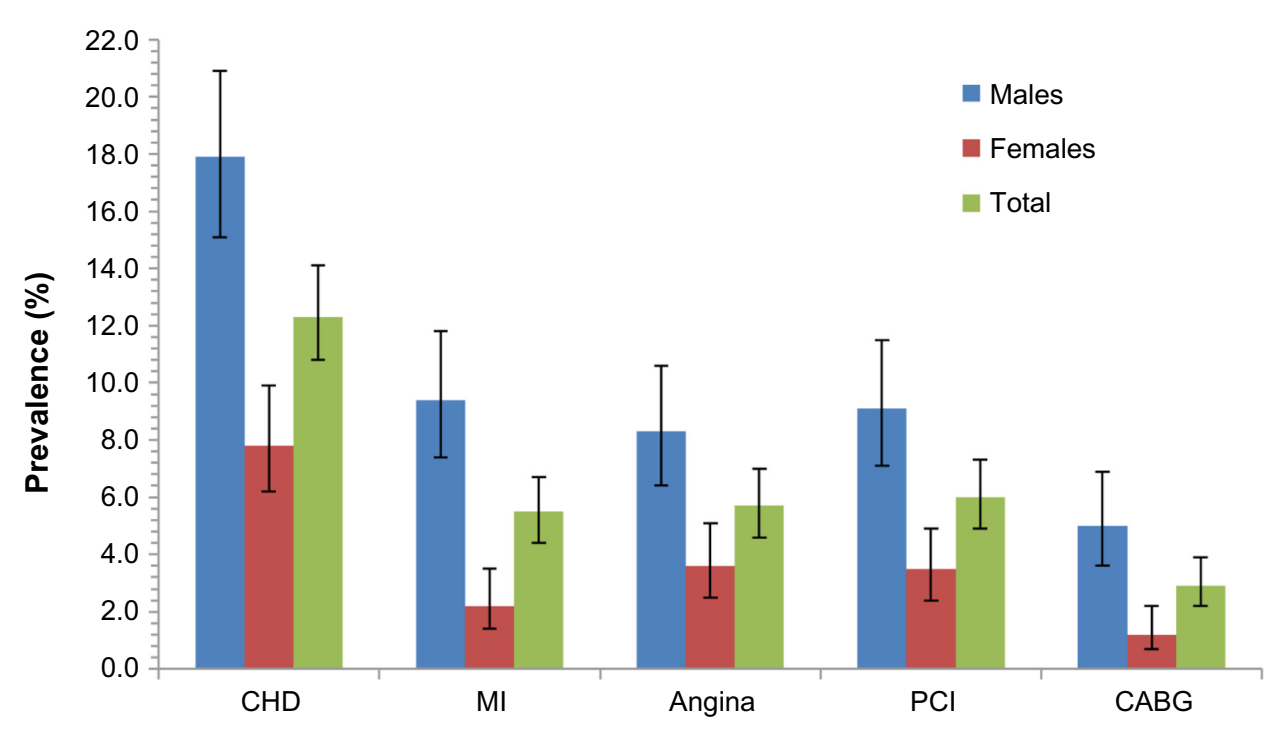

Figure I Prevalence estimates of CHD, adjusted to the WHO world standard population.

Note: The error bars represent the $95 \% \mathrm{Cl}$.

Abbreviations: $\mathrm{CHD}$, coronary heart disease; $\mathrm{MI}$, myocardial infarction; $\mathrm{PCl}$, percutaneous coronary intervention; CABG, coronary artery bypass graft; Cl, confidence interval; WHO, World Health Organization.

the median DBP values were not $(P=0.130)$. No significant differences were found in regard to physical activity, distress, or adherence to an MD.

\section{Multivariate analysis}

Three multivariate regressions are shown in Table 4; the first model includes sociodemographic information, the second also adds behavioral RFs, while the third combines the biological RFs with the aforementioned variables. Model 1 shows that participants with CHD were older and more likely to be males, retired, and less advantaged. Model 2 showed the same effect of age, sex, retirement, and income. It also showed that CHD-positive participants were almost twice more likely to have accumulated more than 30 cigarette-pack-years, and more likely to suffer from abdominal obesity. The last model showed the overall profile of participants living with CHD. Age, sex, and economic situation remained significant, but lifestyle factors were replaced by biological factors: hypercholesterolemia seemed to have the most prominent effect (adjusted odds ratio $[\mathrm{aOR}]=5.22,95 \% \mathrm{CI}=2.99-9.13$ ), followed by hypertension $(\mathrm{aOR}=2.64,95 \% \mathrm{CI}=1.36-5.11)$, having a family history of premature CVD ( $\mathrm{aOR}=2.36,95 \%$ $\mathrm{CI}=1.18-4.72)$, and suffering from diabetes $(\mathrm{aOR}=2.19,95 \%$ $\mathrm{CI}=1.18-4.07)$.

\section{Discussion}

This paper is the first to investigate the prevalence of CHD among Lebanese aged 40 years and above, and to examine the association of CHD with sociodemographics, and behavioral and health-related characteristics.

\section{Prevalence of CHD}

The prevalence of CHDs increased with age and were markedly more abundant in males. However, significant differences between sexes disappeared with older age. This pattern likely reflects unequal distributions of CVD RFs between sexes up to a certain age. In fact, a trend was noticed in our data of females having lower biological RFs, while this advantage leveled off with age (results not shown), a trend that has been found in larger works. ${ }^{25-27}$

Studies measuring the burden of CHD mostly report CHD incidence, whereas only few report CHD prevalence. Also, most studies include different age ranges, and often report only an overall prevalence without the presentation of agespecific rates. The overall prevalence of MI was similar to the one found in Jordanian ${ }^{28}$ and German studies, ${ }^{29}$ which measured the prevalence of prior MI in adults over 40. In the German population having a substantially higher proportion of people in the age group of $\geq 60$ years $(27.6 \%$ vs $11.5 \%$ in Lebanon and $5.4 \%$ in Jordan), ${ }^{30}$ the similarity in prevalence rates suggests an earlier onset of CHD in Middle Eastern countries. Furthermore, when comparing age-specific prevalences of MI and angina, prevalences of MI were higher than recent reports from the UK in all age groups for males and females, but angina seemed to be more prevalent in Lebanon in the younger age groups. ${ }^{31}$ On the other hand, 
Table 3 Differences in sociodemographic characteristics, and lifestyle and biological RFs according to coronary heart disease status

\begin{tabular}{|c|c|c|c|c|c|}
\hline Variables & CHD - $(n=1$ I 79)\% & $C H D+(n=\mid 82) \%$ & $P$-value & OR $(95 \% \mathrm{Cl})$ & $\begin{array}{l}\text { Significance } \\
\text { level }\end{array}$ \\
\hline Age, in years, median (IQR) & $53(45-63)$ & 61 (54-74) & $<0.001$ & $1.04(1.03-1.06)$ & $*$ \\
\hline Age categories & & & $<0.001$ & & \\
\hline 40-50 years & 40.7 & 14.3 & & I & \\
\hline $50-60$ years & 25.4 & 28.6 & & $3.24(1.98-5.29)$ & $*$ \\
\hline $60-70$ years & 16.4 & 22.5 & & $3.93(2.34-6.61)$ & $*$ \\
\hline$\geq 70$ years & 17.6 & 34.6 & & $5.59(3.44-9.08)$ & $*$ \\
\hline Male (vs female) & 46.8 & 66.5 & $<0.001$ & $2.25(1.62-3.13)$ & $*$ \\
\hline Rural (vs urban) & 43.7 & 49.4 & 0.165 & $1.26(0.91-1.73)$ & \\
\hline $\begin{array}{l}\text { Single/widowed/divorced } \\
\text { (vs married) }\end{array}$ & 21.6 & 20.6 & 0.762 & $0.94(0.64-1.39)$ & \\
\hline Work status & & & $<0.001$ & & \\
\hline Working & 53.0 & 43.4 & & I & \\
\hline Not working & 40.1 & 36.3 & & $1.10(0.78-1.56)$ & \\
\hline Retired & 6.9 & 20.3 & & $3.59(2.28-5.65)$ & $*$ \\
\hline Lower than secondary level & 48.0 & 60.7 & 0.002 & $1.67(1.2 \mathrm{I}-2.30)$ & $* *$ \\
\hline $\begin{array}{l}\text { Income/person of the household } \\
\text { lower than the first quartile of } \\
\text { the sample }\end{array}$ & 25.8 & 38.6 & $<0.001$ & I.8I (I.29-2.53) & $*$ \\
\hline Smoking status & & & 0.001 & & \\
\hline Never smoker & 39.4 & 34.1 & & I & \\
\hline Previous smoker & 11.6 & 22.4 & & $2.19(1.39-3.45)$ & $*$ \\
\hline Current smoker & 49.0 & 43.5 & & I.0I $(0.70-1.46)$ & \\
\hline Cigarette smoking & & & $<0.001$ & & \\
\hline Non-cigarette smoker & 53.5 & 41.7 & & I & \\
\hline $0.1-14.9$ cigarette-pack-years & 17.7 & 13.1 & & $0.94(0.56-1.56)$ & \\
\hline I5-29.9 cigarette-pack-years & 9.3 & 8.9 & & $1.22(0.67-2.23)$ & \\
\hline$\geq 30$ cigarette-pack-years & 19.5 & 36.3 & & $2.39(1.64-3.49)$ & $*$ \\
\hline Waterpipe smoking & & & 0.482 & & \\
\hline Non-waterpipe smoker & 80.2 & 83.6 & & I & \\
\hline $0.1-19.9$ WP-years & 8.9 & 5.5 & & $0.57(0.28-1.17)$ & \\
\hline 20-39.9 WP-years & 3.0 & 3.6 & & $1.25(0.53-2.95)$ & \\
\hline$\geq 40$ WP-years & 7.9 & 7.3 & & $0.87(0.46-1.64)$ & \\
\hline BDS-22, median (IQR) & $4.0(1.0-10.0)$ & $4.0(1.0-11.7)$ & 0.954 & $1.01(1.00-1.03)$ & \\
\hline LMDS, $\mathrm{m} \pm \mathrm{SD}$ & $31.8 \pm 4.1$ & $32.5 \pm 4.2$ & 0.071 & $1.04(1.00-1.08)$ & \\
\hline Insufficient physical activity & 70.9 & 74.0 & 0.407 & $1.17(0.8 \mathrm{I}-\mathrm{I} .68)$ & \\
\hline BMI, median (IQR) & $27.27(24.34-30.23)$ & $28.37(25.5 \mathrm{I}-3 \mathrm{I} .46)$ & 0.002 & $1.05(1.02-1.08)$ & $* *$ \\
\hline BMl categories & & & 0.079 & & \\
\hline Normal weight & 30.9 & 23.0 & & I & \\
\hline Overweight & 42.5 & 45.4 & & $1.44(0.97-2.14)$ & \\
\hline Obese & 26.7 & 31.7 & & $1.61(1.05-2.47)$ & $* * *$ \\
\hline$W C, m \pm S D$ & $94.8 \pm 15.5$ & $102.0 \pm 16.0$ & $<0.001$ & $1.03(1.02-1.04)$ & $*$ \\
\hline Hypertension & 39.4 & 81.3 & $<0.001$ & $6.69(4.53-9.89)$ & $*$ \\
\hline SBP, median (IQR) & $12.75(\mid 1.30-14.00)$ & $13.75(12.00-14.50)$ & $<0.001$ & $1.15(1.06-1.24)$ & $*$ \\
\hline DBP, median (IQR) & $8(7-8.5)$ & $7.75(7-8.5)$ & 0.130 & $0.96(0.83-1.10)$ & \\
\hline Diabetes & 14.6 & 42.6 & $<0.001$ & $4.35(3.1 \mathrm{I}-6.08)$ & $*$ \\
\hline RCBG, median (IQR) & $110(97-131)$ & $126(102-161.88)$ & $<0.001$ & $1.01(1.00-1.01)$ & $*$ \\
\hline Hypercholesterolemia & 24.0 & 58.7 & $<0.001$ & $4.50(3.18-6.38)$ & $*$ \\
\hline Hypertriglyceridemia & 17.8 & 44.6 & $<0.001$ & $3.72(2.59-5.33)$ & $*$ \\
\hline Family history of premature CVD & 13.2 & 21.0 & 0.006 & $1.75(1.17-2.61)$ & $* *$ \\
\hline
\end{tabular}

Notes: $* \leq 0.001, * * \leq 0.01, * * * \leq 0.05$.

Abbreviations: CHD, coronary heart disease; OR, crude odds ratio; CI, confidence interval; IQR, interquartile range; BDS-22, Beirut Distress Scale; LMDS, Lebanese Mediterranean Diet Score; BMI, body mass index; WC, waist circumference; SBP, systolic blood pressure; DBP, diastolic blood pressure; RCBG, random capillary blood glucose; CVD, cardiovascular disease; RFs, risk factors; WP, waterpipe; m, mean; SD, standard deviation. 
Table 4 Profile of patients with prevalent CHD

\begin{tabular}{|c|c|c|c|c|c|c|}
\hline \multirow[t]{2}{*}{ Variables } & \multirow{2}{*}{$\frac{\text { Model Ia }}{\text { aOR }(95 \% \mathrm{Cl})}$} & \multirow{2}{*}{$\begin{array}{l}\text { Significance } \\
\text { level }\end{array}$} & \multirow{2}{*}{$\frac{\text { Model } 2^{\mathrm{b}}}{\operatorname{aOR}(95 \% \mathrm{Cl})}$} & \multirow{2}{*}{$\begin{array}{l}\text { Significance } \\
\text { level }\end{array}$} & \multirow{2}{*}{$\frac{\text { Model } 3^{c}}{\operatorname{aOR}(95 \% \mathrm{Cl})}$} & \multirow{2}{*}{$\begin{array}{l}\text { Significance } \\
\text { level }\end{array}$} \\
\hline & & & & & & \\
\hline Age, years & $1.04(1.02-1.05)$ & * & $1.04(1.02-1.06)$ & $*$ & $1.05(1.02-1.08)$ & $*$ \\
\hline Male & $2.32(\mid .49-3.6 I)$ & $*$ & $2.23(1.20-4.15)$ & $* *$ & $4.69(2.49-8.83)$ & $*$ \\
\hline Rural vs urban & - & & - & & - & \\
\hline \multicolumn{7}{|l|}{ Work status } \\
\hline Working & I & & I & & - & \\
\hline Not working & $1.10(0.67-1.81)$ & & I.38 (0.7I-2.69) & & - & \\
\hline Retired & $2.30(1.37-3.85)$ & $* * *$ & $2.81(1.45-5.45)$ & $* * *$ & - & \\
\hline Lower than secondary level & - & & - & & - & \\
\hline $\begin{array}{l}\text { Income/person of the household lower } \\
\text { than the first quartile of the sample }\end{array}$ & $1.75(1.21-2.54)$ & $* * *$ & $1.73(0.07-2.78)$ & $* *$ & $2.21(1.26-3.90)$ & $* * *$ \\
\hline \multicolumn{7}{|l|}{ Cigarette smoking } \\
\hline Non-cigarette smoker & & & I & & - & \\
\hline $0.1-14.9$ cigarette-pack-years & & & $1.08(0.55-2.14)$ & & - & \\
\hline I5-29.9 cigarette-pack-years & & & $1.09(0.45-2.63)$ & & - & \\
\hline$\geq 30$ cigarette-pack-years & & & $2.02(1.19-3.44)$ & $* * *$ & - & \\
\hline BDS-22 & & & - & & - & \\
\hline LMDS & & & - & & - & \\
\hline WC & & & $1.04(1.02-1.05)$ & $*$ & - & \\
\hline BMI & & & - & & - & \\
\hline Hypertension & & & & & $2.64(I .36-5.1 \mathrm{I})$ & $* * *$ \\
\hline Diabetes & & & & & $2.19(1.18-4.05)$ & $* *$ \\
\hline Hypercholesterolemia & & & & & $5.20(2.97-9.07)$ & $*$ \\
\hline Hypertriglyceridemia & & & & & - & \\
\hline Family history of premature CVD & & & & & $2.36(I .18-4.7 I)$ & $* *$ \\
\hline
\end{tabular}

Notes: aRegression Model I included sociodemographic factors: age, sex, region type, marital status, work status, education level, income for each person of the household. ${ }^{b}$ Regression Model 2 included variables entered in Model I, plus lifestyle factors: cigarette-pack-years, BDS-22, LMDS, WC, BMI. 'Regression Model 3 included variables entered in Model 2, plus biological factors: hypertension, diabetes, hypercholesterolemia, hypertriglyceridemia, family history of premature CVD. * $\leq 0.00 \mathrm{I}, * * \leq 0.05$, *** $\leq 0.0 \mathrm{I}$. Abbreviations: CHD, coronary heart disease; aOR, adjusted odds ratio; Cl, confidence interval; BDS-22, Beirut Distress Scale; LMDS, Lebanese Mediterranean Diet Score; WC, waist circumference; BMI, body mass index; CVD, cardiovascular disease.

when comparing to the prevalences in the USA, Lebanese males had higher MI prevalences until the age of $80 .{ }^{32}$ This prematurity in the onset of CHD in the Middle East was well established in the INTERHEART study ${ }^{33}$

\section{Association of socioeconomic status and $\mathrm{CHD}$}

Age and male sex have long been linked with CHD. In our study, these two variables showed significant results in all multivariate models. Another Lebanese study on the socioeconomic disparities in heart disease also found male sex and older age to be nonmodifiable independent RFs. ${ }^{7}$ Rural and urban living did not seem to influence CHD. This could be explained by the small size of the Lebanese territory, the displacements of the Lebanese population, and modernization. Other studies showed only minor influence of habitat location on self-reported morbidity. ${ }^{34}$ On the other hand, retirement increased the odds of belonging to the CHD group, even after adjusting for age. In fact, retirement has been linked to an increase in CVD. ${ }^{35}$ Lower socioeconomic status remained in the multivariate analysis as in other studies from non-Western countries. ${ }^{7,28,36}$ The persistence of the income level even after adjustment for the biological RFs suggests an independent effect of socioeconomic status on CHD.

\section{Association of behavioral RFs and CHD}

In the bivariate analysis, previous smoking, but not current smoking, was associated with CHD; this was previously seen in another local study ${ }^{7}$ and indicates that the presence of CHD might have been an incentive for smoking cessation. Also, we found that accumulating more than 30 cigarettepack-years over the years put people more at risk of CHD compared to nonsmokers, but no effect was found in waterpipe smokers. Although waterpipe smoking has been linked to CVD, a Lebanese study showed that heavy waterpipe smoking only increased the odds of having severe stenosis. ${ }^{37}$ The cigarette's impact remained significant when entered in the multivariate analysis of behavioral RFs, along with WC, but both disappeared from the model when biological RFs were added, showing that the effects of these lifestyle RFs on CHD were probably mediated through biological RFs. BMI did not persist in the multivariate analysis, although 
WC did; same results were found in a large study, which concluded that obesity-related health risk is explained by WC. ${ }^{38}$ Moreover, in the bivariate analysis, better adherence to an MD and higher distress scores were mildly associated with CHD, suggesting a diet modification in CHD patients, and supporting the important role of psychological distress as an RF in the Middle Eastern populations. ${ }^{39}$

\section{Association of biological RFs and CHD}

All biological RFs were strongly associated with CHD in the bivariate analysis. While SBP gave significant results, DBP did not. In fact, systolic hypertension is more common and more strongly associated with cardiovascular complications than diastolic hypertension; it is also more difficult to treat. ${ }^{40}$ This was noticed in our sample where the prevalence of uncontrolled DBP $(24.9 \%, 95 \%$ CI $=21.9 \%-27.9 \%)$ was significantly lower than that of SBP $(43.1 \%, 95 \%$ $\mathrm{CI}=39.7 \%-46.5 \%$ ). Our final multivariate regression model confirms the relevance of the classic biological RFs in Lebanon after adjustment for sociodemographics and lifestyle RFs. They appeared to be strongly associated with CHD except for hypertriglyceridemia; this could be explained by the strong clustering of hypercholesterolemia and hypertriglyceridemia in our sample. Finally, family history of premature CVD seemed to be an important independent predictor of CHD. ${ }^{6}$

In Lebanon, primary health care centers receive mostly the underprivileged who seem to be more prone to CHD. Our results should thus encourage the incorporation of care managers into the primary health care centers, whose role would be to support physicians in the management of patients with CVD RFs; this intervention is feasible and has proven its efficacy in improving health behaviors and reaching better compliance with care recommendations, consequently improving clinical indicators and achieving better results. ${ }^{41}$

The results of this study should be interpreted in light of the following strengths and limitations. The strengths of this study include the generalizability of its conclusions conferred by the sample size and the representativeness of the study sample, making it the first study to report a national estimate for CHD prevalence. Moreover, the questionnaire captured several aspects allowing us to explore the relationship of CHD with demographics, socioeconomics, and behavioral and health-related factors. Nevertheless, the study has some limitations that ought to be reported. The cross-sectional nature of this study limits the assessment of temporality and therefore causality. Nonetheless, a temporal relationship is plausible for associations such as family history, age, sex, and education level. Also, the population-based setting of this study does not allow the measurement of asymptomatic CHD prevalence. Possible misclassification bias could have been introduced since data concerning CHD and most RFs were self-reported. Yet, a previous study suggested the reliability and validity of the reporting of heart disease in the Lebanese population. ${ }^{42}$ Also, the Rosa Angina score was used to determine angina prevalence, and two measurements of BP and one measurement of RCBG were done. Finally, excessive alcohol consumption could not be accounted for in this study as it is believed that alcohol would be largely underreported for religious reasons.

\section{Conclusion}

This study was the first nationwide endeavor to investigate CHD prevalence and to construct the profile of Lebanese adults who should be targeted for secondary prevention. CHD seemed to appear more prematurely than in Western populations and seemed to be more prevalent in males. This study also confirms the relevance of the classic RFs of CHD and their applicability to the Lebanese population. Our findings suggest that targeted interventions aiming to reduce these classic RFs should be conducted to decrease the burden of CHD, especially in economically disadvantaged people.

\section{Acknowledgments}

The Foundation thanks all employees and students who participated in data collection and implementation of this study, particularly in isolated rural areas despite the political and security situation. Grateful thanks and recognition to Dr Ghada Al Sayed for her involvement and coordination.

The following medical students are acknowledged; Abdel Majid Abdel Kader, Abeer Shbaro, Alaa Mesri, Alamir Noureddine Alayoubi, Ali Ibrahim, Ali Jaafar, Amal Younes, Amani Chahine, Baraah Nachar, Elia Awad, Elias Assaf, Farah Assi, Farah Mansour, Faten Mansouri, Fatima Al Atab, Hasan Farhat, Hasan Joumaa, Hussein Yassin, Iman Jaafar, Imtissal Krayem, Inaam Issa, Issa Harmouche, Joyce Saliba, Khouloud Hassan, Laila Tabash, Lama Labaki, Lama Mortada, Layal Baddour, Liliane Issa, Loujayne Osman, Malak Hasan, Manal Ghandour, Mariam Abboud, Mariam Fakih, Maritta Khawand, Marwa Harakeh, Maryam Sinno, Mhammad Darwich, Mohamad Ayoub, Mohammad Khodor, Mona Fakih, Narjes Jaafar, Norma Dahdah, Nour Labaki, Nour Mahdi, Omar El Mawas, Oula Mesri, Patrick Sarkis, Rana Kandar, Rasheed BouDiab, Richard Bedran, Rima El 
Baset, Rita Daher, Samar Siblani, Shahah Hashem, Souad BouHarb, Widad Chami, Wissam Yassin, Younes Mahmoud, Youness Hassan, Zainah Majed, Zeina Nasser.

The study was conducted in 60/100 circumscriptions as independent study by the Foundation-Medical Research Institutes $\left(\mathrm{F}-\mathrm{MRI}^{\circledR}\right)$ as sole sponsor with its own human, technical, and financial supports.

\section{Disclosure}

The authors report no conflicts of interest in this work.

\section{References}

1. Murray CJ, Vos T, Lozano R, et al. Disability-adjusted life years (DALYs) for 291 diseases and injuries in 21 regions, 1990-2010: a systematic analysis for the Global Burden of Disease study 2010. Lancet. 2012;380(9859):2197-2223.

2. Yusuf S, Reddy S, Ounpuu S, Anand S. Global burden of cardiovascular diseases: part I: general considerations, the epidemiologic transition, risk factors, and impact of urbanization. Circulation. 2001;104(22): 2746-2753.

3. Okrainec K, Banerjee DK, Eisenberg MJ. Coronary artery disease in the developing world. Am Heart J. 2004;148(1):7-15.

4. Cheng A, Braunstein JB, Dennison C, Nass C, Blumenthal RS. Reducing global risk for cardiovascular disease: using lifestyle changes and pharmacotherapy. Clin Cardiol. 2002;25(5):205-212.

5. Almahmeed W, Arnaout MS, Chettaoui R, et al. Coronary artery disease in Africa and the Middle East. Ther Clin Risk Manag. 2012;8: 65-72.

6. Abchee A, Puzantian H, Azar ST, et al. Predictors of coronary artery disease in the Lebanese population. Thromb Res. 2006;117(6): 631-637.

7. Ramahi T, Khawaja M,Abu-Rmeileh N, Abdulrahim S. Socio-economic disparities in heart disease in the Republic of Lebanon: findings from a population-based study. Heart Asia. 2010;2(1):67-72.

8. Farah R, Zeidan RK, Chahine MN, et al. Prevalence of stroke symptoms among stroke-free residents: first national data from Lebanon. Int $J$ Stroke. 2015;10(Suppl A100):83-88.

9. Sibai AM, Tohme RA, Mahfoud Z, Chaaya M, Hwalla N. Non-Communicable Diseases and Behavioral Risk Factor Survey: Comparison of Estimates Based on Cell Phone Interviews with Face to Face Interviews. Beirut, Lebanon: WHO Lebanon office; 2009.

10. O’Brien E, Asmar R, Beilin L, et al. European Society of Hypertension recommendations for conventional, ambulatory and home blood pressure measurement. J Hypertens. 2003;21(5):821-848.

11. Rose GA. The diagnosis of ischaemic heart pain and intermittent claudication in field surveys. Bull World Health Organ. 1962;27:645-658.

12. Ainsworth BE, Haskell WL, Herrmann SD, et al. 2011 Compendium of physical activities: a second update of codes and MET values. Med Sci Sports Exerc. 2011;43(8):1575-1581.

13. World Health Organization. Global Recommendations on Physical Activity for Health. Geneva: World Health Organization; 2010. Available from: http://www.ncbi.nlm.nih.gov/books/NBK305057/. Accessed September 20, 2015

14. McGorrian C, Yusuf S, Islam S, et al. Estimating modifiable coronary heart disease risk in multiple regions of the world: the INTERHEART Modifiable Risk Score. Eur Heart J. 2011;32(5):581-589.

15. Joseph S, Pascale S, Georges K, Mirna W. Cigarette and waterpipe smoking decrease respiratory quality of life in adults: results from a national cross-sectional study. Pulm Med. 2012;2012:868294.

16. Barbour B, Saadeh N, Salameh PR. Psychological distress in Lebanese young adults: constructing the screening tool "BDS-22". Int J Cult Ment Health. 2012;5(2):94-108.
17. Issa C, Jomaa L, Salamé J, et al. Females are more adherent to Lebanese Mediterranean diet than males among university students. Asian Pac J Health Sci. 2014;1(4):345-353.

18. Vasan RS, Larson MG, Leip EP, Kannel WB, Levy D. Assessment of frequency of progression to hypertension in non-hypertensive participants in the Framingham Heart Study: a cohort study. Lancet. 2001;358(9294):1682-1686.

19. Stern MP, Williams K, Haffner SM. Identification of persons at high risk for type 2 diabetes mellitus: do we need the oral glucose tolerance test? Ann Intern Med. 2002;136(8):575-581.

20. National Cholesterol Education Program (NCEP) Expert Panel on Detection, Evaluation, and Treatment of High Blood Cholesterol in Adults (Adult Treatment Panel III). Third report of the National Cholesterol Education Program (NCEP) Expert Panel on Detection, Evaluation, and Treatment of High Blood Cholesterol in Adults (Adult Treatment Panel III) final report. Circulation. 2002;106(25):3143-3421.

21. Chobanian AV, Bakris GL, Black HR, et al. Seventh report of the Joint National Committee on prevention, detection, evaluation, and treatment of high blood pressure. Hypertension. 2003;42(6):1206-1252.

22. Central Administration of Statistics, Ministry of Social Affairs. Population. Available from: http://www.cas.gov.lb/index.php/demographicand-social-en/population-en. Accessed December 31, 2015.

23. Ahmad O, Boschi-Pinto C, Lopez A, Murray C, Lozano R, Inoue M. Age Standardization of Rates: A New WHO Standard. Geneva, Switzerland: World Health Organization; 2001. Available from: http://www.who.int/ healthinfo/paper31.pdf. Accessed September 1, 2015.

24. Rumeau-Rouquette C, Breart G, Padieu R. Methods in Epidemiology: Sampling, Investigations, and Analysis. Paris, France: Flammarion; 1985.

25. Jousilahti P, Vartiainen E, Tuomilehto J, Puska P. Sex, age, cardiovascular risk factors, and coronary heart disease: a prospective follow-up study of 14,786 middle-aged men and women in Finland. Circulation. 1999;99(9):1165-1172.

26. DECODE Study Group. Age- and sex-specific prevalences of diabetes and impaired glucose regulation in 13 European cohorts. Diabetes Care. 2003;26(1):61-69.

27. Kearney PM, Whelton M, Reynolds K, Muntner P, Whelton PK, He J. Global burden of hypertension: analysis of worldwide data. Lancet. 2005;365(9455):217-223.

28. Nsour M, Mahfoud Z, Kanaan MN, Balbeissi A. Prevalence and predictors of nonfatal myocardial infarction in Jordan. East Mediterr Health J. 2008;14(4):818-830.

29. Gößwald A, Schienkiewitz A, Nowossadeck E, Busch MA. Prevalence of myocardial infarction and coronary heart disease in adults aged 40-79 years in Germany: results of the German Health Interview and Examination Survey for adults (DEGS1). Bundesgesundheitsblatt Gesundheitsforschung Gesundheitsschutz. 2013;56(5-6):650-655.

30. United Nations. World Population Prospects; The 2015 Revision; Key Findings and Advance Tables. 2015. New York, NY: United Nations, 2015. Available from: http://esa.un.org/unpd/wpp/Publications/Files/ Key_Findings_WPP_2015.pdf. Accessed December 31, 2015.

31. Bhatnagar P, Wickramasinghe K, Williams J, Rayner M, Townsend N. The epidemiology of cardiovascular disease in the UK 2014. Heart. 2015;101(15):1182-1189.

32. Mozaffarian D, Benjamin EJ, Go AS, et al. Heart disease and stroke statistics-2015 update: a report from the American Heart Association. Circulation. 2015;131(4):e29-e322.

33. Yusuf S, Hawken S, Ounpuu S, et al. Effect of potentially modifiable risk factors associated with myocardial infarction in 52 countries (the INTERHEART study): case-control study. Lancet. 2004;364(9438):937-952.

34. Sabbah I, Vuitton D-A, Droubi N, Sabbah S, Mercier M. Morbidity and associated factors in rural and urban populations of South Lebanon: a cross-sectional community-based study of self-reported health in 2000. Trop Med Int Health. 2007;12(8):907-919.

35. Olesen K, Rugulies R, Rod NH, Bonde JP. Does retirement reduce the risk of myocardial infarction? A prospective registry linkage study of 617511 Danish workers. Int J Epidemiol. 2014;43(1):160-167. 
36. Reddy KS. Cardiovascular disease in non-Western countries. $N$ Engl $J$ Med. 2004;350(24):2438-2440.

37. Sibai AM, Tohme RA, Almedawar MM, et al. Lifetime cumulative exposure to waterpipe smoking is associated with coronary artery disease. Atherosclerosis. 2014;234(2):454-460.

38. Janssen I, Katzmarzyk PT, Ross R. Waist circumference and not body mass index explains obesity-related health risk. Am J Clin Nutr. 2004;79(3):379-384.

39. Gehani AA, Al-Hinai AT, Zubaid M, et al. Association of risk factors with acute myocardial infarction in Middle Eastern countries: the INTERHEART Middle East study. Eur J Prev Cardiol. 2014;21(4):400-410.
40. Lloyd-Jones DM, Evans JC, Larson MG, O’Donnell CJ, Roccella EJ, Levy D. Differential control of systolic and diastolic blood pressure: factors associated with lack of blood pressure control in the community. Hypertension. 2000;36(4):594-599.

41. Ciccone MM, Aquilino A, Cortese F, et al. Feasibility and effectiveness of a disease and care management model in the primary health care system for patients with heart failure and diabetes (Project Leonardo). Vasc Health Risk Manag. 2010;6:297-305.

42. Halabi S, Zurayk H, Awaida R, Darwish M, Saab B. Reliability and validity of self and proxy reporting of morbidity data: a case study from Beirut, Lebanon. Int J Epidemiol. 1992;21(3):607-612.

\section{Publish your work in this journal}

Vascular Health and Risk Management is an international, peerreviewed journal of therapeutics and risk management, focusing on concise rapid reporting of clinical studies on the processes involved in the maintenance of vascular health; the monitoring, prevention and treatment of vascular disease and its sequelae; and the involvement of metabolic disorders, particularly diabetes. This journal is indexed on PubMed Central and MedLine. The manuscript management system is completely online and includes a very quick and fair peer-review system, which is all easy to use. Visit http://www.dovepress.com/ testimonials.php to read real quotes from published authors. 